\title{
Corrigendum
}

\section{Vitamin D, causation, conflict of interest and other issues - CORRIGENDUM}

\author{
Oliver Gillie
}

First published online 28 January 2015

doi:10.1017/S1368980014002304 Published online by Cambridge University Press 05 November 2014

In my article ${ }^{1}$, which challenged the conclusions of two articles published in the Lancet", the term "reverse causation" should be attributed only to the article by Autier et $a l^{2}$ and not to Bolland et $a l^{3}$.

I further welcome the opportunity to clarify issues raised regarding my conflict of interest declaration. I have worked full time on vitamin D and sunshine issues for 11 years without funding. A summary of relevant financial aspects of this activity is given below:

1. Commercially sponsored meetings In 2005 I organized a meeting on vitamin D and sunlight attended by more than a hundred doctors, scientists and media people. The meeting took place at the House of Commons, on parliamentary premises provided without fee thanks to the interest and support of Dr Ian Gibson MP. Expenses of the meeting, amounting to about $£ 15,000$, were provided by the Sunlight Research Forum, a lobbying body supported by the sunlamp industry. The money was spent largely on travel and subsistence costs of bringing speakers from the United States and Europe. Speakers and subjects were decided entirely by me. Sunlamps were not one of the subjects addressed, nor were they spoken of. Neither I nor anyone else received any payment for the considerable work involved in organizing this meeting, nor have I at any time received any payment from the Sunlight Research Forum.

A second sponsored meeting on the same subject attended by more than a hundred people, mostly health writers, took place under the auspices of the Guild of Health Writers in January 2014 at the King's Fund. Sponsorship to the value of about $£ 12,000$ was provided by The Vitamin D Mission, a commercial lobbying body concerned with childhood nutrition supported by Cow and Gate, and Kelloggs, among others. Speakers and subjects were all decided by me without any input from the Mission. Neither I nor anyone else in the Guild of Health Writers received any payment from the sponsors, nor did the Guild make any financial profit from the sponsorship.

2. Vitamin D Company

From October 2011 to August 2013, I worked with the Vitamin D Company to help sell vitamin D mini-tablets providing 2000 or 5000 IUs vitamin D. Such higher dose tablets were at that time difficult to obtain, and I was anxious to do what I could to remedy this. I resigned from the company in August 2013. I was never paid anything by the company and do not retain any stock.

3. Sun Run Community Interest Company

In 2014 I set up a community interest company called Sun Run CIC, which is strictly regulated by law as a charitable enterprise and is organizing a $10 \mathrm{Km}$ run in Greenwich Park on 26 July 2015. The aim of the Sun Run is to publicise the health benefits of sunshine while providing all necessary advice to avoid sunburn. In return for publicity, sponsorship will be sought from approved sources in various forms such as goodie bags. Profits from running the event, including participant fees (£16-18) and any sponsorship monies, will be used to pay Sun Run CIC executives, including myself, for the work undertaken to organise the event. Remaining profits will be held by Sun Run CIC and distributed solely to charitable bodies according to the law.

4. To provide a balanced view of any perceived conflict of interest, I would also like to explain that I have considerable unfunded expenses from working in this area. For example, I have written two detailed academic monographs, Sunlight Robbery ${ }^{4}$ and Scotland's Health Deficit ${ }^{5}$, which are available for viewing on line. These monographs cost me personally $£ 2,500$ each to print and distribute. They have been published under the imprint of Health Research Forum, an unregistered charity which has never had any funds. I have sometimes described myself as the director of Health Research Forum, but this is a post which carries no salary and provides no financial benefits of any kind. Spending full time in 
advocacy of benefits of vitamin D and sunshine rather than working full time on freelance journalism and writing has resulted in a substantial, annual loss of income, which is possible only with the dedicated support of my wife, to whom I give profound thanks.

5. In referring to "delicate professional issues" (Acknowledgements), I did not have in mind any kind of professional impropriety. Study of causation is a basic activity of scientists in attempting to make sense of the world. When such studies make an error in scientific reasoning, we should try to understand how this has happened. This is what I meant by a delicate professional issue, and it involves examining what led to such an error, made not only by the authors of the articles but also by the professional editors and referees who reviewed the manuscript.

\section{References}

1. Gillie O Controlled trials of vitamin D, causality and type 2 statistical error. Public Health Nutrition, published online by Cambridge University Press 06 November 2014, doi:10.1017/ S1368980014002304

2. Autier PBM, Pizot C \& Mullie P (2013) Vitamin D status and ill health: a systematic review. Lancet Diabetes Endocrinol 2, 76-89.

3. Bolland MJ, Grey A, Gamble GD et al. (2014) The effect of vitamin D supplementation on skeletal, vascular, or cancer outcomes: a trial sequential meta-analysis. Lancet Diabetes Endocrinol 2, 307-320.

4. Gillie O Sunlight Robbery: Health Benefits of sunlight are denied by current public health policy in the UK. Health Research Forum Occasional Reports No 1, 2005. (available at www.healthresearchforum.org.uk).

5. Gillie O Scotland's health deficit: an explanation and a plan. Health Research Forum Occasional Reports No 3, 2008. (available at www.healthresearchforum.org.uk). 